\title{
Necrotizing fasciitis following measles vaccine administration: a case report
}

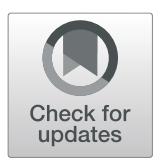

\author{
E. E. Isere ${ }^{1 *}$, A. A. Fatiregun ${ }^{1}$, O. A. Olubosede ${ }^{2}$, M. O. Dosumu ${ }^{1}$ and E. O. Bello ${ }^{2}$
}

\begin{abstract}
Background: The occurrence of adverse events following immunization (AEFI) in national immunization programmes is very rare; however, if they occur causality assessment is conducted to identify the associated cause. In the report, we describe a case of severe necrotizing fasciitis in the left arm of a 9-month old boy following administration of the measles vaccine.

Case presentation: A 9-month old boy presented with swelling on the left upper arm and adjoining the chest area, low-grade continuous fever, frequent passage of loose watery stool and persistent cries $24 \mathrm{~h}$ after measles vaccine was administered on the left upper arm. On examination, he was mildly pale, febrile, anicteric. Extensive erythema of the left upper arm occurred thereafter with extensive scalded skin lesions involving the deltoid area, the upper chest wall and arm. This was followed by desquamation of the affected areas and severe necrosis. A diagnosis of severe necrotizing fasciitis was made. A causality assessment was conducted by the state AEFI committee using the detailed AEFl investigation forms to identify the cause of the incidence.

Conclusion: Here we present a rare case of necrotizing fasciitis which could have been caused by incorrect use of reconstituted measles vaccine. Hence we recommend training of routine immunization service providers on proper vaccine management as well as intensified supervision of immunization sessions.
\end{abstract}

Keywords: Adverse event following immunization, Necrotizing fasciitis, Measles vaccination

\section{Background}

Necrotizing fasciitis (NF) is a the life threatening softtissue infection, that is characterized by inflammation and subsequent necrosis of the muscles, fascia, subcutaneous fat and the epidermis in some cases [1-3]. Initial symptoms are nonspecific: the most frequently reported signs are fever, tenderness, erythema, and pain [3, 4]. Commonly recognized predisposing events include surgery, trauma, ruptured varicella blisters, and intramuscular injection. The common predisposing factors in newborns include omphalitis, circumcision, bullous impetigo, rectal temperature measurement and electrode placement for vital signs monitoring [3-7].However, few cases of postvaccination NF, an adverse events following immunization (AEFI), have been reported in infants in literature $[3,4]$.

Measles is an acute viral infectious disease and an important cause of childhood morbidity and mortality [8]. Routine vaccination of children at 9 months according

\footnotetext{
* Correspondence: elvisisere@gmail.com

${ }^{1}$ World Health Organization, Ondo State Field office, Akure, Nigeria Full list of author information is available at the end of the article
}

to the national immunization schedule of Nigeria with the live-attenuated measles vaccines has substantially reduced the risk of measles infection and measles deaths annually [8-10]. However, in some very rare occasion, cases of adverse events following immunization may occur. AEFI are any untoward medical occurrences which follow immunization and which do not necessarily have a causal relationship with the use of the vaccine [11]. These adverse events may be any unfavourable sign, abnormal laboratory finding, symptom or disease occurring after immunization [11].

In this report, we present a case of necrotizing fasciitis in a 9-month old child after receiving the measles vaccine, and the outcome of causality assessment.

\section{Case presentation}

A 9-month old boy presented at a hospital in a south western state of Nigeria, with a swollen left upper arm adjoining the chest, low-grade continuous fever $\left(38.1^{\circ} \mathrm{C}\right)$, frequent passage of loose watery stool and persistent cries for more than $3 \mathrm{~h}$. Child had been immunized about $24 \mathrm{~h}$ earlier. 
The mother reported that the symptoms were observed $2 \mathrm{~h}$ after the child was vaccinated with the measles vaccine at a private hospital. The child was one of three children reported to have been vaccinated with measles vaccine at a private hospital during the immunization clinic session.

On examination, he was mildly pale, febrile and anicteric. He was moderately dehydrated; mildly dyspnoeic with normal heart sound, heart rate of 148 beats/ min, breath sound was vesicular and respiratory rate of $54 \mathrm{cy}-$ cles per minute. He was well nourished as the weight was appropriate for age. There was extensive swelling with skin discolouration (hyperemia) involving the entire left upper arm, sparing the distal third of the forearm and hand. There was also swelling of the upper part of the anterior chest wall. The swelling was firm and mildly tender. There was no history of adverse reaction to immunization or any form allergic reaction.

A day after admitting the child, extensive erythema of the left upper arm and anterior area of the chest was observed with extensive scalded skin lesion involving the deltoid area, the upper chest wall and arm (Fig. 1). Desquamation of the affected areas was observed presenting like severely burned skin from a hot liquid. There was darkening and hardening of the skin over the affected area on the arm with eventual severe necrosis up to a depth of about $5 \mathrm{~mm}$ thereafter (Figs. 2 and 3). A diagnosis of severe necrotizing fasciitis was made.

Radical debridement of necrotic tissues was carried out under general anaesthesia. Child was also transfused with blood. Daily dressing of the wound was done and antibiotics administered were intravenous metronidazole $(20 \mathrm{mg} / \mathrm{kg} /$ day in 3 divided doses) and ceftazidime (100 mg/ kg/ day in 3 divided doses). Child was referred to University College Hospital, Ibadan, a teaching hospital in a neighbouring state where skin grafting was performed. Presently, child have recovered and he is fully healthy.

\section{Causality assessment}

A causality assessment was conducted by the state AEFI committee using the detailed AEFI investigation forms using WHO AEFI causality assessment methodology $[12,13]$.Visits were made to the private hospital where the child was reported to have received the vaccine. The routine immunization focal person in the facility was interviewed. Assessment of available cold chain devices for vaccine storage was also carried out. The knowledge and skills of health workers in vaccine handling, management and administration were assessed [14-16]. In addition, the caregivers of two other children immunized during the session were recalled and interviewed. The case of interest was the first child to be vaccinated with measles vaccine during the immunization clinic while the second child, a 9 months old female who received vaccination from the same measles vial had fever and abscess formation at the site of immunization only however, the third child who was also vaccinated during the immunization clinic was healthy and without symptoms. The third child was found to be vaccinated with measles vaccine from a newly reconstituted measles vaccine vial different from the measles vaccine vial used for the other two children on the day of the immunization clinic. Incision and drainage procedure was carried out for the second child with wound dressing conducted for two weeks who thereafter recovered fully.

The findings from the investigation indicated that a programmatic error may have been responsible for the reactions.We found that two children were vaccinated with a measles vaccine that have been reconstituted for a period of $>6 \mathrm{~h}$. The measles vaccine administered to these children was reconstituted 7 days ago and used during the previous immunization clinic with the leftover stored in a refrigerator within the hospital. This was due to poor knowledge and skill in vaccine management and administration among health workers who

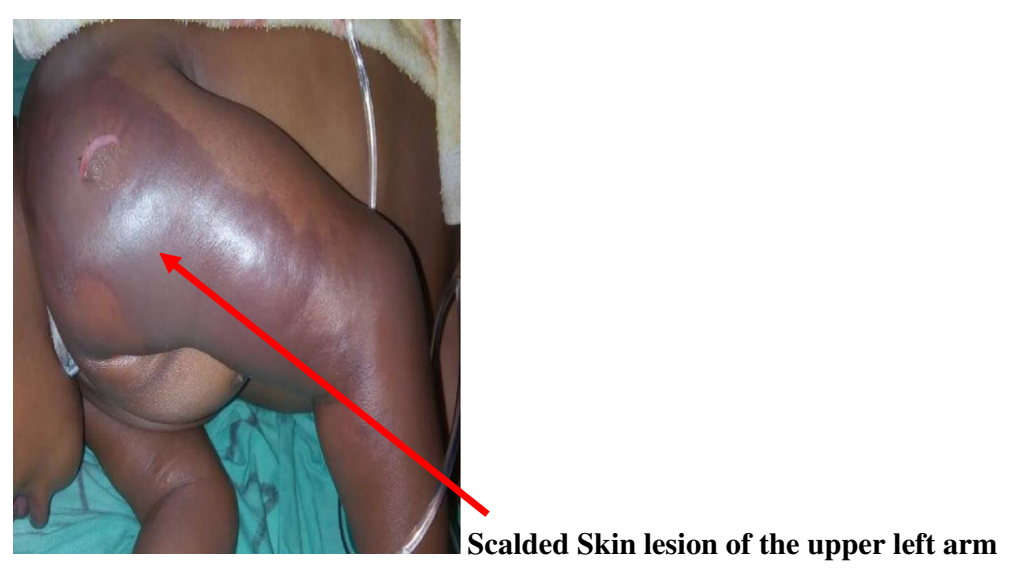

Fig. 1 Scalded Skin lesion of the upper left arm 


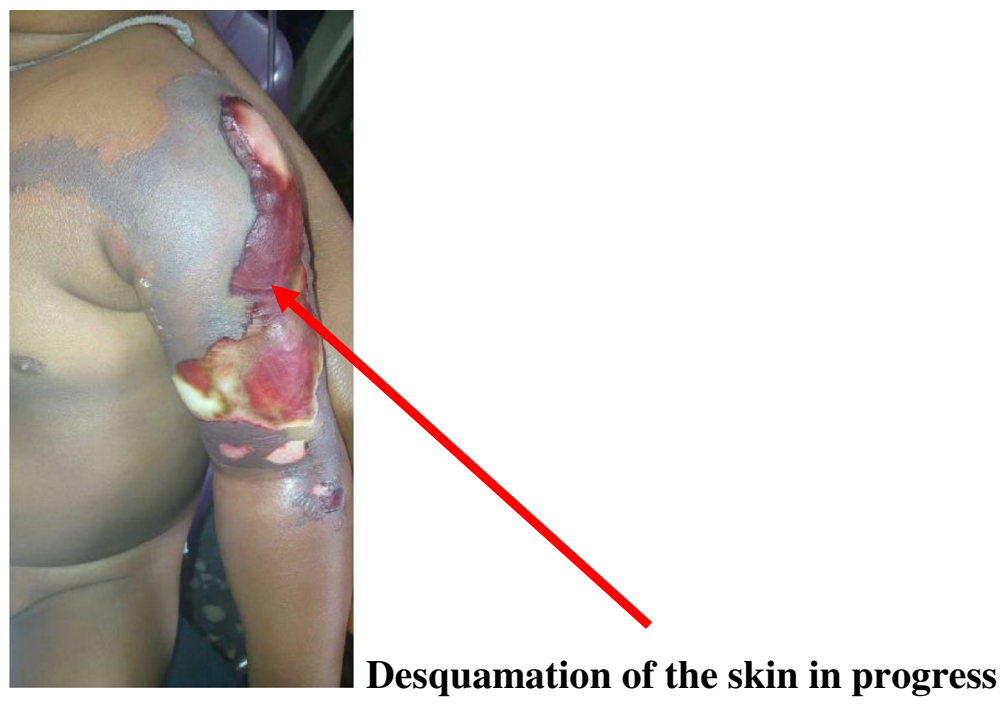

Fig. 2 Desquamation of the skin in progress

administered the vaccine. Other key issues identified includes poor documentation of vaccination activities using the recommended data management tools resulting in difficulty to tracked other children vaccinated with other vaccines for further investigation and poor vaccine storage system at the private hospital as the hospital lacks the recommended Solar Direct Drive (SDD) refrigerator for proper vaccine storage. Also, effort to retrieve the samples of the left-over doses of the vaccine in the opened vials for laboratory investigation proved abortive as the used/empty vial of the vaccine was said to have been discarded by the health workers immediately after the immunization clinic. Furthermore, blood samples collected from the child with NF by the attending physician during the preliminary case management at a local hospital for microbiological culture investigation shows contamination of culture plate as samples were not properly stored during the culture process due to lack of the required facility to perform the test at the hospital.

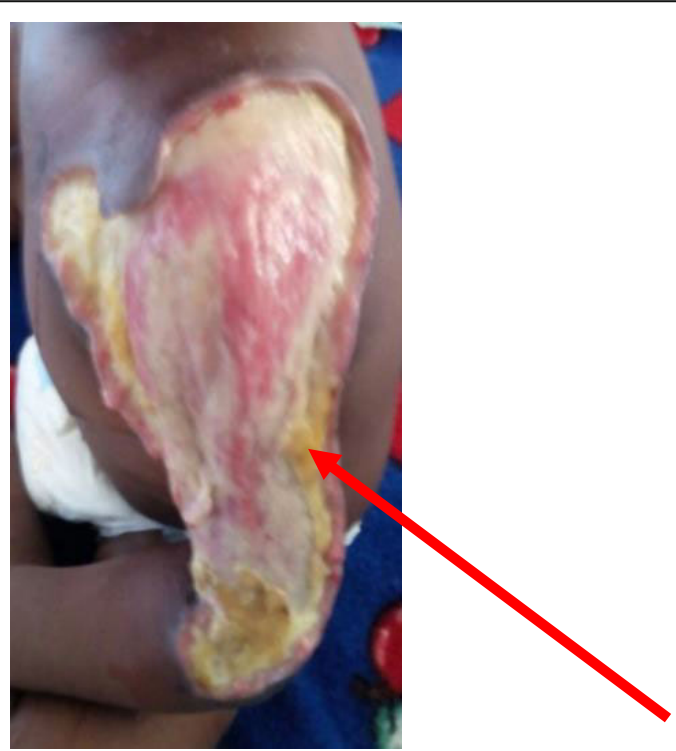

Necrolysis of the tissue of the affected area

Fig. 3 Necrolysis of the tissue of the affected area 


\section{Discussion and conclusion}

Necrotizing fasciitis in infants has been well documented in literature with several predisposing factors identified [5-7]. However, in this infant, no obvious predisposing factors other than the measles vaccination in the affected arm could be identified.

Several clinical manifestations in this case are consistent with what have been reported by previous authors. Thema et.al, [3] in a case report of NF following BCG vaccination reported fever, pain and erythematous swelling of the outer aspect of the middle third of the left arm with sloughing and necrosis. Similarly, Lemerechal et.al [4] reported fever, mildly painful swelling and erythema on the affected area with local necrosis of $\sim 3 \mathrm{~mm}$ in diameter. The clinical sign of passage of loose stool and moderate dehydration in this case is not consistent with previous reports. However, Zundel et.al [17] have reported that clinical signs of NF in infants most times are non-specific with fever, erythema, pain, tenderness as the most frequently reported symptoms.

Broad spectrum antibiotic is recommended for use in NF because of the wide range of organisms such as streptococci, staphylococci, gram negative rods and anaerobes that could be involved. [18, 19]. Although many studies have favoured the use of antibiotic combinations that included clindamycin [2-4], some other studies did not while one study found that it was not sensitive and had to be changed with the availability of sensitivity report [4]. The antibiotic used in the case was intravenous metronidazole and ceftazidime; and child responded with good clinical improvement. Clindamycin was not used because it was not readily available in our locality.

From our findings from the causality assessment, we presumed that contamination of the vial of vaccine with Staphylococcus aureus and possibly other organism particularly group A Streptococcus (GAS) should have occurred. According to World Health Organization (WHO), all reconstituted vaccines are expected to be discarded after $6 \mathrm{~h}$ or at the end of every immunization session or whichever comes first [20]. It is well documented in literature that when reconstituted vaccines are stored beyond $6 \mathrm{~h}$ of reconstitution contrary to the recommendation, contamination with Staphylococcus aureus and other organisms such as the GAS can occur $[20,21]$. This is because these vaccines do not contain preservatives [15]. It has been reported that when a reconstituted vaccine is contaminated, the organism grows rapidly and produces toxins that could be responsible for the type of necotizing lesion observed in the present case $[1,20,21]$.

Incorrect use of reconstituted measles vaccine could be responsible for the case of necrotizing fasciitis in this report. Hence, we recommend regular training of immunization providers on vaccine handling, management and administration. We also recommend intensified supportive supervision, especially to private hospitals during the conduct of routine immunization sessions to avert future immunization programme error.

\section{Abbreviations}

AEFl: Adverse Events Following Immunization; BCG: Bacille de Calmette et Guérin; GAS: Group A Streptococcus; NF: Necrotizing fasciitis; WHO: World Health Organization

\section{Acknowledgements}

We thank the patient and the family, staff members of pediatrics unit, State Specialist Hospital, Akure who managed the child.

Authors' contributions

EEI, AAF, OAO, MOD and OEB were responsible for the conceptual design while EEI produced the initial draft of the manuscript, which was edited by all authors. All authors read and approved the final manuscript.

\section{Funding}

This study was not funded.

\section{Availability of data and materials}

Data sharing is not applicable to this article as no datasets were generated or analysed during the current study.

Ethics approval and consent to participate

Not applicable

\section{Consent for publication}

Written informed consent was obtained from the parent (mother) of the child for publication of this case report and other accompanying images.

\section{Competing interests}

The authors declare that they have no competing interests.

\section{Author details}

${ }^{1}$ World Health Organization, Ondo State Field office, Akure, Nigeria.

${ }^{2}$ Department of Paediatrics, State Specialist Hospital, Akure, Ondo State, Nigeria.

Received: 25 May 2018 Accepted: 4 June 2019

Published online: 14 June 2019

\section{References}

1. Goldwag DA, Purcell TB. Necrotizing fasciitis in the pediatric age group: report of a case. J Emerg Med. 1990;8:299e304.

2. Al-Ramzi A, Kassem M, Adel KM. Necrotizing fasciitis with toxic shock syndrome in 5 month old baby: a case report. Future Dental J. 2017;3:80-2.

3. Thapa R, Mallick D, Biswas B. Necrotizing fasciitis following BCG vaccination. Indian Pediatr. 2011:48(3):235-7.

4. Lemaréchal A, Zundel S, Szavay P. Pediatric necrotizing fasciitis: Restitutio ad Integrum after early diagnosis and aggressive surgical treatment. Eur J Pediatr Surg Rep. 2016:4:34-6.

5. Hsieh WS, Yang PH, Chao HC, Lai JY. Neonatal necrotizing fasciitis: a report of three cases and review of the literature. Pediatrics. 1999;103:e53.

6. Weber DM, Freeman NV, Elhag KM. Periumbilical necrotizing fasciitis in the newborn. Eur J Pediatr Surg. 2001;11:86-1.

7. Nazir Z. Necrotizing fasciitis in neonates. Pediatr Surg Int. 2005;21:641-4.

8. Park K. Park's Textbook of Preventive and Social Medicine. 21st edn. Jabalpur, Madhya Pradesh: Banarsidas Bhanot; 2011. p. 502-607.

9. Weldegebriel GG, Gasasira A, Harvey P, Masresha B, Goodson JL, Pate MA, Abanida $E$, Chevez A. Measles resurgence following a nationwide measles vaccination campaign in Nigeria, 2005-2008. J Infect Dis. 2011;204(Suppl 1): S226-31.

10. Onoja AB, Adeniji AJ, Faneye A. Measles complications in a Nigerian hospital setting. Clin Rev Opin. 2013;5(2):18-23.

11. World Health Organization. Causality assessment of adverse events following immunization: user's manual for the revised WHO classification. 
[Available on http://www.who.int/vaccine_safety/publications/gvs_aefi/en/. Accessed 31 Oct 2017.

12. Aderibigbe SA, Osagbemi GK, Bolarinwa OA. Adverse event following immunization in a Nigerian tertiary health institution. Am J Sci Ind Res. 2010;1(3):496-9.

13. Lawan UM, Amole GT, Wali NY, Jahun MG, Jibo AM, Nakore AA. Pattern of adverse events following immunization in nourished and malnourished infants in Kano, NorthWestern Nigeria. Sahel Med J. 2016;19(3):131-5.

14. Ogunyemi RA, Odusanya OO. A survey of knowledge and reporting practices of primary healthcare workers on adverse experiences following immunisation in alimosho local government area, Lagos. Niger Postgrad Med J. 2016;23:79-85.

15. Federal Ministry of Health. Immunization training module for Inactivated Polio Vaccine introduction in Nigeria: Facilitator's guide. NPHCDA Pp 31, 2015

16. CIOMS/WHO. Definition and application of terms for vaccine pharmacovigilance. Report of CIOMS/WHO Working Group on Vaccine Pharmacovigilance. Geneva, Council for International Organizations of Medical Sciences, 2012. Available on: www.cioms.ch/index.php/component/ booklibrary/?task=view\&ltemid=\&id=45\&catid=58. [Accessed 11 Nov 2017]

17. Zundel S, Lemaréchal A, Kaiser P, Szavay P. Diagnosis and treatment of pediatric necrotizing fasciitis: a systematic review of the literature. Eur J Pediatr Surg. 2017;2:127-37.

18. Chelsom J, Halstensen A, Haga T, Hoiby EA. Necrotizing fasciitis due to group a streptococci in western Norway. Incidence and clinical features Lancet. 1994;344:1111-5. https://doi.org/10.1016/S0140-6736(94)90629-7.

19. Al Shukry S, Ommen J. Necrotizing fasciitis- report of ten cases and review of recent literature. J Med Life. 2013;16(2):189-94.

20. World Health Organization. Immunization, Vaccines and Biological. Available from: http://www.who.int/immunization/en/. [Last Accessed 11 Nov 2017].

21. Misiakos EP, Bagias G, Patapis P, Sotiropoulos D, Kanavidis P, Machairas A. Current concepts in the management of necrotizing fasciitis. Frontiers in Surgery. 2014;1(36):1-10. https://doi.org/10.3389/fsurg.2014.00036.

\section{Publisher's Note}

Springer Nature remains neutral with regard to jurisdictional claims in published maps and institutional affiliations.

Ready to submit your research? Choose BMC and benefit from:

- fast, convenient online submission

- thorough peer review by experienced researchers in your field

- rapid publication on acceptance

- support for research data, including large and complex data types

- gold Open Access which fosters wider collaboration and increased citations

- maximum visibility for your research: over $100 \mathrm{M}$ website views per year

At $\mathrm{BMC}$, research is always in progress.

Learn more biomedcentral.com/submissions 